\title{
Cos/emocions de les celebritats d'internet en la societat 4.0 a la Xina*
}

\author{
Adrián Scribano \\ CONICET (UNIVERSIDAD DE BUENOS AIRES) \\ adrianscribanofagmail.com \\ Zhang Jingting \\ SHANGHAI INTERNATIONAL STUDIES UNIVERSITY \\ felisazhang007@igmail.com
}

Rebut: 28/03/2019

Acceptat: 19/09/2019

\begin{abstract}
RESUM
Les celebritats d'internet, com a grup d'estreles produïdes per l'economia de mercat i internet, mostren la transformació i la situació actual de la cultura d'internet i les xarxes socials a la xina. En el físic i la imatge que projecten aquestes celebritats, si bé són úniques, hi ha implícit un simbolisme cultural. La revolució 4.0 ens porta noves pràctiques socials i maneres d'interactuar amb les xarxes socials com a protagonistes. En aquest article investigarem les interseccions i ruptures entre cos-individu, cossubjectiu i cos-social (Scribano, 2007) de les estreles d'internet xineses, i les articulacions i relacions entre el cos-imatge i el seu cos-en-moviment. Analitzem plataformes de xarxes socials xineses com WeChat (微信), Sina Weibo (新浪微博) o Douyin per rastrejar vincles entre la sociabilitat, les experiències i les sensibilitats socials de les celebritats d'internet i la seua influència en la societat 4.0 xinesa.
\end{abstract}

Aquest article (a) examina les xarxes socials xineses com a plataforma virtual de les estreles d'internet; (b) aprofundeix en les imatges i pràctiques de les estreles d'internet; (c) subratlla la relació entre el cos, la sensació i la percepció quant a les celebritats socials; (d) mostra els tipus de sociabilitat i sensibilitats socials exhibides per les celebritats en la societat 4.0.

Paraules clau: celebritats d'internet, cos, sensibilitat, la Xina.

ABSTRACT. Body/Emotions of Internet Celebrities in the Society 4.0 in China

Internet celebrities, as a group of stars spawned by the market economy and The Internet, reveal both the state of Internet culture and the transformation of mass media in China. The bodies and pictures of these 'celebs', while unique, also take on a cultural symbolism. The 4.0 Revolution is the carrier of social practices and kinds of interaction in which the social media play a very special role. In this paper we will focus on the intersections and ruptures between the body-individual, body-subjective and body-social (Scribano, 2007) of Chinese Internet celebrities and the articulations and links between body-image and their body-in-movement. With the introduction of Chinese social media platforms such as WeChat (微信), Sina Weibo (新浪微博), Douyin, we try to trace links between the sociability, experiences and social sensibilities of the Internet celebrities and their influence on Society 4.0 .

This paper: (a) looks at the Chinese social media as a virtual platform for the Internet celebrities; (b) delves into the images and practices of the Internet celebrities; (c) highlights the link between body, sensation and perception regarding social celebrities; (d) shows the kinds of sociability and social sensibilities exhibited by celebrities in China's Society 4.0.

Keywords: internet celebrities, body, sensibility, China.

\footnotetext{
*Article traduït de l'anglès. El text original està publicat a Debats. Journal on Culture, Power and Society. Annual Review 4.
} 


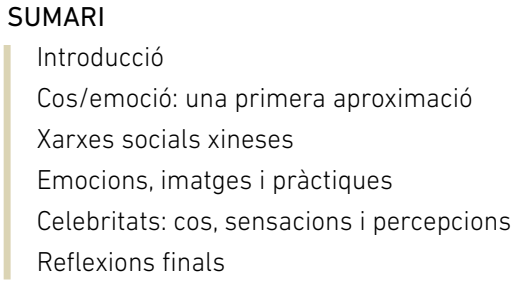

Autor per a correspondència / Corresponding author: Adrián Scribano, CIES-ESTUDIOS SOCIOLÓGICOS EDITORA. Billinghurst 1260 Piso 4, Dpto. A (CP. 1413)- Ciudad Autónoma de Buenos Aires.

Suggeriment de citació / Suggested citation: Scribano, A. y Jingting, Z. (2019) Cos/emocions de les celebritats d'internet en la societat 4.0 a la xina. Debats. Revista de cultura, poder i societat, 131(2), 117-129. DOI: http://doi.org/10.28939/iam.debats.133-2.10

\section{INTRODUCCIÓ}

La immensa popularitat de les xarxes socials ha sigut sens dubte un dels esdeveniments més rellevants de principis del segle xxI. Han sigut protagonistes en esdeveniments que van de la Primavera Àrab a Ocupa Wall Street, passant pels indignats o l'ús dels mòbils per a comprar qualsevol cosa. En aquest context, la Xina, com a «fàbrica del món», s'ha transformat en els últims quaranta anys en una societat industrialitzada i altament tecnològica gràcies a l'aplicació de la Reforma i a la política d'obertura formulada per Deng Xiaoping en 1978. Va ser ell qui va introduir reformes capitalistes en un país comunista d'economia comunista planificada, que van traure més de set-cents quaranta milions de persones de la pobresa. ${ }^{\mathbf{1}}$

Amb l'entrada en el segle xxI, la Xina s'enfronta també a la revolució 4.0. Ciutats intel-ligents, indústries intel-ligents, sistemes ciberfísics (internet de les coses, computació en el núvol), webots, automatització total o revolució 4.0 són termes als quals ens hem acostumat. També al fenomen de les estreles d'internet, que s'ha convertit en una verdadera indústria a la Xina.

1 Estadístiques de l'agència de notícies Xin Hua. Disponible en http://www.xinhuanet.com/politics/2018 12/10/c_1123833866.htm
En l'article «Bodies of Digital Celebrities», Pearl i Polan (2015) insisteixen en el fet que en l'era digital les noves indústries mediàtiques poden exalçar persones normals fins a convertir-les en excepcionals. Així i tot, no podem ignorar la importància dels cossos.

En aquesta era digital, tan centrada en allò virtual, és fàcil pensar que les celebritats han passat a ser una cosa inefable (...). Però inclús ara que els mitjans poden crear una celebritat a distància, a través del temps i l'espai, sovint la qüestió s'acaba reduint als cossos. (Pearl i Bolan, 2015: 190)

Les autores també mencionen la vinculació entre tradicions culturals i qüestions com el cos, la corporealitat i la materialitat.

Gran part del poder de les persones famoses radica en la seua vitalitat (la seua naturalitat? la seua vivesa?) (p. 191)

Wang Junbin (2018) analitza el concepte dels mitjans grassroots, segons el qual qualsevol persona pot arribar a ser famosa. No obstant això, aquestes estreles necessiten amplis coneixements per a cobrir les demandes del públic. Així, resulta essencial que estiguen al dia de les últimes tendències i notícies, així com del llenguatge social que s'utilitza en les distintes plataformes (Facebook, Youtube, LINE, Instagram, etc.). 
Lin (2018), per la seua banda, investiga la interpretació del cos dins de les pràctiques d'autogestió de l'aparell governamental del Partit-Estat de la Xina, en particular en el cas de les dones famoses. Lin usa expressions com «escenificació del cos», «defensa del cos» $\mathrm{i}$ «instrumentalització del cos» per a descriure com Ye Haiyan, clar exemple de celebritat femenina, treballa amb el seu cos per a assolir els seus objectius.

Ye ha utilitzat el seu cos com a escenari i canal de transgressió política, ha reivindicat el seu cos en pro dels drets sexuals $i$ ha instrumentalitzat el seu cos per a aconseguir objectius relacionats amb el seu activisme. En aquest sentit, les pràctiques de representació del cos d'aquesta celebritat d'internet mai són externes a la lògica del Partit-Estat, sinó internes al seu projecte governamental, la qual cosa planteja la qüestió de la resistència en relació amb la microfísica del cos. (Lin, 2018: 777)

Xu Xu i Stephen Pratt estudien la generació Y xinesa $i$ es valen de la teoria de l'autocongruència per a entendre la relació entre promotors i turistes potencials i per a avaluar l'eficàcia del suport. Ells creuen que en el sector turístic els operadors majoristes haurien de considerar la possibilitat que els influencers promoguen productes i destinacions turístiques en les xarxes socials. Zhang Yanhui i Chen Fuwen (2018) examinen la influència de les celebritats d'internet en el món de la publicitat i com han canviat la consciència dels consumidors guiant-los cap a certes formes de consum.

En 2015 el primer ministre xinés Li Keqiang va proposar un pla estratègic per a la Xina denominat «Made in China 2025» (中国制造2025), els objectius del qual són, entre altres, (1) incrementar el percentatge de components tecnològics crítics produïts a la Xina fins al quaranta per cent el 2020 i fins al setanta per cent el 2025, i (2) que l'economia se centre en el mercat de l'alta tecnologia, com les indústries farmacèutica, automobilística i aeroespacial, en els semiconductors, la informàtica, la robòtica, etc. ( $\mathrm{Li}$, 2018). Així, aquest pla es considera la versió xinesa de la Quarta Revolució Industrial, semblant al concepte de la Indústria 4.0 alemanya. «Made in China 2025» pretén impulsar la innovació i eliminar els obstacles per al desenvolupament industrial, de manera que la Xina deixe de ser la fàbrica del món per a convertir-se en una potència industrial de ple dret.

Segons l'informe «2018 China's internet industry report», indicatiu del desenvolupament econòmic de les estreles d'internet xineses:

Al maig de 2018, les estreles d'internet amb una base de seguidors superior a 100.000 persones havien incrementat aquesta base un $51 \%$ en l'últim any. El seu nombre total de fans va augmentar un $25 \%$ i va assolir 588 milions. $^{2}$

L'auge de les celebritats d'internet ha tingut una enorme influència en la societat xinesa. En l'actualitat, ja disposen d'un públic immens, que probablement continuarà creixent.

Aquestes figures públiques tenen gran influència i impacte social a la Xina, sobretot a nivell moral. Estableixen els estàndards i la direcció moral de la societat, i modelen les sensibilitats polítiques. Com que el/els cos/cossos i la/les societat/societats són un objecte d'investigació sistemàtica on l'afectivitat i les sensibilitats estan molt presents, les nombroses teories sobre les emocions poden classificar-se en tres grups: determinisme, construccionisme social i interacció social.

Gross i Feldman Barrett (2011), en un intent d'avaluar les diferents perspectives en la «generació» i/o «regulació» de les emocions, classifiquen les perspectives actuals per a l'estudi de les emocions en quatre grans grups: (1) models d'emocions bàsiques, (2) models d'avaluació, (3) models de construcció psicològica i (4) models de construcció social.

2 «2018 China's internet industry report» (en línia), http://www. iresearchchina.com/content/details8 40769.html, consultat el 21 de març de 2019. 
Scribano porta més d'una dècada explicant la importància del «gir existencial» en la teoria social, al-legant que hi ha una relació estreta entre l'estudi dels cossos i el de les emocions (1998, 2005, 2010, 2012) i subratllant la importància d'explorar la intersecció entre aquestes obres, tot analitzant la funció que exerceixen els colors i els sentiments en relació amb les qüestions que plantegen (2007).

No obstant això, quan parlem d'estreles xineses, cal no oblidar que s'ha estudiat poc la relació entre els seus cossos, les seues emocions i la seua influència social. En The Internet and New Social Formation in China (2016) es mostra com els consumidors d'entreteniment formen un públic específic gràcies a les tecnologies en l'era actual de la societat de xarxes. També s'investiga com els fans es converteixen en públic destinatari. Per la seua banda, Cyber-nationalism in China: Challenging Western media portrayals of internet censorship in China (2012) descriu les emocions dels usuaris d'internet a la Xina (la seua ràbia, les seues actituds, etc.) i compara el liberalisme de les comunitats xineses i les occidentals:

L'avanç de les tensions entre els bloguers xinesos i els mitjans occidentals ha posat de manifest la gran diferència en la interpretació de les naturaleses del nacionalisme i la censura entre la Xina i Occident. (Jiang, 2012: 3)

Hi ha una estreta relació entre els canvis de sensibilitats i la transformació de la denominada «societat 4.0».

Amb el desenvolupament de les últimes tecnologies, hem passat a ser una societat 4.0, en què els dispositius mòbils (telèfons, tauletes tàctils) s'han convertit en espais de producció, edició i emmagatzematge d'imatges. Scribano (2017) suggereix que estem passant per una etapa en què els nostres sentits convergeixen en el món de la tecnologia en busca de descobriments i autenticitat.

Les xarxes socials xineses, com Wechat, QQ o Weibo, constitueixen un exemple paradigmàtic del mode metonímic amb què les pràctiques estan canviant la nostra manera de forjar vincles socials, experiències i sensibilitats. La consultora McKinsey \& Company afirma el següent:

La indústria 4.0, com a nova fase en la digitalització del sector industrial, ve impulsada per quatre motors: l'augment en el volum de dades que manegen les empreses industrials, uns equips informàtics cada vegada més potents i barats, la capacitat per a l'anàlisi i processament de dades i la constant millora de la interacció de les persones amb les màquines, robots $\mathrm{i}$ impressores $3 \mathrm{D} .^{3}$

Les xarxes socials han nascut i s'han globalitzat en el context de convergència d'aquestes tendències: l'ús generalitzat de les xarxes socials, la revolució 4.0 i el sorgiment dels «creadors d'imatges». És en aquest context on es pot apreciar l'emergència de les societats 4.0. Podem distingir pràctiques que tipifiquen les xarxes socials en general (màrqueting digital, campanyes polítiques, de caritat, etc.). També hi ha altres pràctiques que s'estan consolidant o ja estan consagrades.

Aquest article a) observa les xarxes socials xineses que serveixen com a plataforma virtual per a les celebritats d'internet; b) indaga en les imatges i pràctiques de les celebritats d'internet; c) assenyala la relació entre cos, sensació i percepció en relació amb l'escena de celebritats socials, i d) revela quin tipus de socialització i sensibilitats socials apareixen en la societat 4.0 mitjançant celebritats.

\section{COS/EMOCIÓ: UNA PRIMERA APROXIMACIÓ}

La presència de celebritats en les xarxes socials té lloc en i a través de cossos/emocions. Les sensibilitats associades a la presència d'aquests cossos ens permet entendre millor les societats.

3 Are you ready for the 4th industrial revolution?. McKinsey \& Company. En línia: https://www.mckinsey.com/businessfunctions/operations/how-we-help-clients/capability-centernetwork/overview, consultat el 20 de març de 2019. 
Un camí per a entendre el paper del cos consisteix a observar les distàncies i els ponts entre cos-individu, cos-subjectiu i cos-social. Això implica subratllar les relacions entre l'experiència del cos com a organisme, l'experiència del cos com a acte reflexiu i la pràctica del cos com a construcció social. El cos-individu es refereix a una lògica filogenètica, a l'articulació entre allò orgànic i l'entorn; el cos-subjectiu parteix de l'autorreflexió, entenent el «jo» com a centre de gravetat a través del qual es formen múltiples subjectivitats, i finalment, el cos-social és la societat feta carn, per dir-ho així (sensu Bourdieu).

Aquestes tres pràctiques bàsiques del cos organitzen la lògica de regulació dels sentits i al mateix temps estan organitzades per ella. L'evolució gradual i la constant metamorfosi de les sensibilitats són formes d'apropiar-se de l'energia del cos, les connexions entre distintes sensacions del cos que, en el seu conjunt, constitueixen un dels pilars de dominació i també d'autonomia.

Aquest tipus de redescripció ontològica requereix un debat sobre les diferències entre energies corporals i socials, que la falta d'espai ens impedeix discutir ací. Per a mantenir $l^{\prime}$ «estat de les coses» assignades al cos individual, resulta essencial que l'energia del cos es convertisca en un objecte tant de producció com de consum. Ací, l'energia del cos és la font de l'energia social que trobem en la societat. La capacitat de planificar, executar i resoldre les conseqüències de les accions dels agents constitueix l'energia social.

El segon camí per a entendre el rol del cos consisteix a traçar i reconstruir el que ja sabem sobre el cos a través del cos-imatge, el cos-pell i el cos-moviment. Aquestes tres formes d'inscriure allò corporal en una narrativa ofereixen una anàlisi reconstructiva de com podem entendre els aspectes corporals de l'impacte de les estreles d'internet en la sociabilitat, la sensibilitat i les experiències de la vida quotidiana com a fenòmens socials.

El cos-imatge és un indicador del procés «jo veig que em veuen»; el cos-pell es refereix al procés pel qual una persona «sent naturalment» el món, i el cos-moviment és la inscripció del cos en una sèrie de possibles accions. Aquestes tres maneres de reconstruir les experiències del cos poden entendre's com a camins per a les anàlisis i interpretacions de com les formes del cos es mostren en l'escena social. Trobem tensions i processos entre les parts socials del cos, el cos i la postura, el cos com a estructura social significativa, l'elaboració de la imatge del cos que cada agent ha de construir i gestionar.

Els sentits semblen naturals, però també són resultat d'un procés de construcció social, que és on es construeix el cos-pell. En conseqüència, la sociabilitat i les sensibilitats socials es consoliden com la manera «natural» de «sentir el món».

El cos-moviment és una mediació tant del poder com de la impotència del cos i les energies socials. Els cossos poden actuar de distintes maneres, és a dir, poden actuar en funció de les energies socials i la inèrcia social. En altres paraules, hi ha diverses maneres d'actuar que encarnen les geometries socials de desplaçament, així com la inèrcia social. En aquest procés, la vista, l'olfacte, el tacte, l'oïda i el gust convergeixen en una possible sociabilitat i mostren recursos socials per a regular les sensacions.

Així que, en altres paraules, aquestes accions acosten o distancien els cossos de la mencionada dialèctica. Les sensacions, que són l'abans i el després de les percepcions, donen pas a les emocions, que poden entendre's com la manifestació de l'acció i l'efecte dels sentiments. Es basen en com sentim el món i conformen les percepcions associades a les emocions com a construcció social.

Al mateix temps, els sentits orgànics socials també permeten la mobilització de trets únics i irrepetibles, mentre duen a terme el «treball inadvertit» d'incorporar allò social a través de les emocions.

Una forma privilegiada de connexió entre l'acció collectiva i les fantasies i il-lusions socials radica en el fet que el cos és el locus de conflicte i d'orde. És el lloc 
i el topos (del grec, То́лоऽ) del conflicte, per on passa gran part de la lògica dels antagonismes contemporanis. Des d'aquest punt de vista, podem observar la formació d'una economia política de moralitat, és a dir, sensibilitats, pràctiques i manifestacions que posen nom a la dominació. En aquest sentit, entenem que els mecanismes que determinen què és tolerable des d'un punt de vista social es regeixen per un conjunt de pràctiques fetes amb el propòsit d'evitar sistemàticament el conflicte social. Els processos que desplacen les conseqüències de l'antagonisme es presenten com a escenaris espectaculars despresos (desincrustats) en el temps i l'espai, que permeten tant a l'individu com a la societat acceptar la idea que la vida social sempre adquireix una forma determinada.

També hi ha recursos per a regular les sensacions. Consisteixen en processos de selecció, classificació i elaboració de percepcions determinades i distribuïdes socialment. La regulació implica tensió entre els sentits, percepcions i sentiments que organitzen maneres diferents de «veure's a un mateix en el món» i d'«apreciació en el món» per a persones i grups de persones.

Les cadenes i els esquemes cognitivoafectius que connecten (i desconnecten) les pràctiques socials com a narratives i visions del món fetes carn són processos que caracteritzem com a ideològics. Els mecanismes i recursos identificats són una frontissa procedimental de la qual pengen les interaccions entre emocions, cossos i històries. Els mecanismes de sostenibilitat social dels sistemes no operen ni directament ni explícitament com «temptatives de control», ni «a nivell profund» com a processos amb eixos de persuasió. Al contrari, aquests mecanismes funcionen de manera «pràcticament inadvertida» en els camins trillats pel costum, dins dels marcs del sentit comú, a través de la construcció de sensacions que pareixen ser el més «íntim» $\mathbf{i}$ «singular» que posseeix cada individu com a agent social. Els mitjans de comunicació ofereixen a gent corrent l'oportunitat de convertir-se en estreles i exercir la seua influència com a agents socials. Els seus comportaments i pràctiques socials afecten les emocions i accions dels seus fans.
La política de les emocions requereix una reglamentació que decidisca com es produeix i s'aconsegueix la sostenibilitat de l'orde social. En aquest sentit, entenem que els mecanismes de sostenibilitat social s'estructuren entorn d'una sèrie de pràctiques que s'han arrelat i el principal objectiu de les quals és l'elusió sistemàtica del conflicte social.

Les formes de sociabilitat $i$ experiència es tensen i es retorcen com si estigueren constretes en una cinta de Moebius amb les sensibilitats que emergeixen des dels dispositius de regulació i els mecanismes abans mencionats. La necessitat de distingir i vincular les possibles relacions entre sociabilitat, experiència $i$ sensibilitats socials resulta crucial en aquest punt. La sociabilitat expressa de quina manera viuen i coexisteixen interactivament els agents. L'experiència és una forma d'expressar la importància adquirida en estar físicament prop d'altres persones, com a resultat d'experimentar el diàleg entre el cos individual, el cos social i el cos subjectiu, d'una banda, i l'apropiació natural de les energies corporal i social, de l'altra. Perquè el cos siga capaç de reproduir l'experiència i la sociabilitat, ha de produir energia corporal, però també consumir-ne. Aquesta energia pot entendre's com la força necessària per a mantenir l'estat «natural» de les coses en un funcionament sistemàtic. Al mateix temps, l'energia social que es mostra a través del cos social es basa en la manera en què l'energia individual es gasta i es distribueix a través del moviment i l'acció.

Així, les sensacions es distribueixen d'acord amb les formes específiques de capital corporal, i l'impacte del cos en la sociabilitat i l'experiència revela una distinció entre el cos de l'aparença, el cos de la carn i el cos del moviment. Les sensibilitats socials actualitzen contínuament les trames emocionals que sorgeixen de les formes acceptades i acceptables de sensacions. Són un «més aquí» i un «més enllà» de les interrelacions entre sociabilitat i experiència. Les sensibilitats es formen $i$ reformen a partir de les superposicions contingents i estructurals, adoptant distintes formes de connexió/ desconnexió entre les diverses maneres de produir i reproduir les polítiques dels cossos i les emocions. 
La política de les sensibilitats s'entén com un conjunt de pràctiques socials cognitivoafectives que tendeixen a produir, gestionar i reproduir horitzons d'acció, disposició i cognició. Aquests horitzons es refereixen (1) a l'organització de la vida quotidiana (rutines quotidianes, vigília/son, menjar/abstinència, etc.); (2) a les informacions per a ordenar preferències $i$ valors (adequat/inadequat; acceptable/inacceptable; suportable/insuportable), i (3) als paràmetres per a la gestió del temps/espai (desplaçament/emplaçament; muralles/ponts; gaudi).

En aquest punt adquireixen especial rellevància tres conceptes: les «pràctiques del voler», les «pràctiques del sentir» i les «pràctiques intersticials». Les pràctiques del sentir són les que impliquen conjunts heterogenis de relacions entre sensacions i emocions. Les pràctiques intersticials són les relacions socials que trenquen l'economia política de la moral i estructuren sensibilitats. Les pràctiques del voler es refereixen a les possibles relacions entre esperança, amor i gaudi, i són relacions socials que connecten la relació «jo-tu-un altre». Potser les associacions entre les mencionades pràctiques, els mecanismes de sostenibilitat social i els recursos per a regular les sensacions ens ajuden a entendre millor l'estat de les sensibilitats socials.

En la secció següent reconstruïm els escenaris i contextos on es duen a terme les pràctiques d'aquests cossos dins d'internet.

\section{XARXES SOCIALS XINESES}

És ben sabut que la Xina, el major mercat de xarxes socials del món, difereix molt d'Occident, ja que no té Facebook, Twitter ni Youtube. Quines xarxes usa la gent a la Xina? En la llista «Top 10 Social Media Sites to Connect with Chinese Consumers» ${ }^{\mathbf{4}}$ apareixen les següents: WeChat, Sina Weibo, Youku, Miaopai i

4 Top 10 Social Media Sites to Connect with Chinese Consumers. En https://smallbiztrends.com/2017/07/chinese-social-mediamarketing.html
Yizhibo, Douban, DianPing, Renren, Tencent Weibo, PengYou, Diandian.

WeChat, també conegut com Weixin, és una aplicació multifuncional de missatges de veu i de text. Es va inventar el 2011 i en l'actualitat compta amb més de mil milions d'usuaris actius mensualment (Lie i Cao, 2014). Sina Weibo, que significa «microblog», és com una barreja de Twitter i Facebook. El contingut de Sina Weibo està sempre en ràpida evolució, i les estreles tenen els seus seguidors i el seu espai per a discutir sobre temes candents en Weibo. Youku és semblant a YouTube i ofereix vídeos sobre diversos temes. Miaopai i Yizhibo són plataformes que ofereixen retransmissions en directe i vídeos curts. Douban és un espai on la gent pot compartir opinions sobre llibres, pel-lícules, música, etc. Dianping té funcions semblants a les de Yelp i TripAdvisor, i també permet als usuaris avaluar restaurants. Renren funciona de manera molt pareguda a Facebook, però no té tanta activitat com Weibo o WeChat. Tencent Weibo també és un microblog on les persones usuàries poden compartir vídeos, fotos i missatges de text de fins a cent quaranta caràcters. PengYou («amic», en xinés) és una plataforma amb funcions socials i és un altre producte de l'empresa que va inventar Tencent Weibo.

Una estrela d'internet és algú que deu la seua fama principalment a la seua presència en internet. Fa referència a una persona que és popular en la xarxa per un esdeveniment o patró de comportament que influeix en la societat (que tendeix a copiar el seu ídol). Les estreles d'internet participen activament en les xarxes socials i experimenten una metamorfosi, ja que passen de ser un fenomen de les xarxes socials a ser influencers socials, polítics i econòmics.

Les emocions, l'estètica i els valors de les estreles estan canviant patrons de consum, estils de vida i idees de la població, i exerceixen una profunda influència en la societat xinesa. Zhang i Seta (2018) analitzen la situació i les funcions de les estreles de la xarxa o whanghong (terme en xinés mandarí per a aquests ídols moderns) en la cultura de les comunitats de base. Ser una ciberestrela a la Xina s'ha convertit 
en una «professió» rendible, un model a imitar, un subproducte moralment qüestionable de les economies d'internet, i en general un fenomen social molt debatut entre els usuaris locals. Els autors opinen que la popularitat dels whanhong sorgeix de les xarxes socials xineses $i$ de narratives de professionalitat $i$ aspiracions econòmiques que arriben al públic de la Xina contemporània.

Segons l'informe «Report on internet attitudes in China 2018», $\mathbf{5}$ els temes més discutits van ser «nova era», «bona vida» $\mathbf{i}$ «la política universal dels dos fills». La «nova era» és un concepte general xinés que engloba unes condicions de vida millors basades en la innovació i la internacionalitat, una educació millor i unes relacions més justes entre gèneres. «Fills, joventut, treball i menjar»s'han convertit en «els quatre components més importants d'una bona vida». En 2016, Xina va introduir la política universal dels dos fills: «salut» $i$ «marit» es van convertir en els principals factors que van fomentar el desig de tenir fills. Un altre extrem que es recalca en l'informe és que hi ha dos grans comunitats semàntiques en l'àmbit digital a Xina. Una d'elles se centra en «una nova era de diversificació social», mentre que l'altra cobreix les estreles de la nova era, que són joves, impulsives, patriòtiques i compromeses amb la responsabilitat social. Així, les estreles de la societat digital tenen un marge més gran per a influir en els altres mitjançant les eines de les xarxes socials del país, i contribueixen així a la nova era xinesa.

\section{EMOCIONS, IMATGES I PRÀCTIQUES}

Xina ha presenciat canvis dramàtics durant els últims quaranta anys. Si ens fixem en l'experiència de tres generacions ( $\mathrm{X}, \mathrm{Y}$ i Z $)$, es veu clarament com la transformació del país ha canviat la vida de la gent

5 《中国网络社会心态报告（2018）》发布三大话题引发关 注，中国新闻网，2019年01月21日. Tres temes del Report of the attitudes of internet in China 2018. Pàgina web de notícies xineses. 21 de gener de 2019. (en línia) https://www.pishu.com. $\mathrm{cn} /$ skwx_ps/bookdetail?SitelD=14\&ID=10197082 Consultat el 21 de març de 2019 i ha modelat la seua manera de veure el món. La generació X (de principis-mitjans dels anys seixanta a principis de la dècada dels huitanta) va nàixer durant la Revolució Cultural xinesa (1966-1976). La seua experiència educativa i la seua forma de vida es van veure enormement influïdes per la política. Les persones que pertanyen a aquesta generació van créixer amb la idea que la lleialtat a l'Estat i a les seues institucions seria recompensada. Després, amb la Reforma i la política d'obertura en els anys huitanta, molts elements occidentals van tenir un gran impacte a Xina amb l'arribada de la cultura pop, el cine i les marques dels Estats Units, la vida nocturna, el llenguatge de la joventut d'Occident. Xina també va desenvolupar una important cultura del telèfon mòbil, i prompte va aconseguir el major nombre d'usuaris de mòbil del món. Així, la generació Y (gent nascuda entre 1980 i 1995) va créixer en ple canvi social, durant la política del fill únic xinesa introduïda l'any 1979, per la qual cosa la majoria són fills únics. Com que s'han criat amb l'amor i atenció de dos progenitors i quatre iaios, generalment són gent molt segura de si mateixa i amb una gran autoestima.

Per la seua banda, la generació Z (de mitjans dels noranta a mitjans del 2000) també es va convertir en un fenomen social. Com a conseqüència de la florent economia de Xina i el seu ràpid desenvolupament tecnològic, tenen distints hàbits de vida i de consum. La generació $Z$ és la primera generació xinesa a nàixer en un país completament modern i digitalitzat, per la qual cosa són persones molt connectades i disposades a compartir els seus sentiments a través de les xarxes socials. Moltes d'elles emeten en directe en Douyin, Taobao, Weixin, etc. Tenen els seus fans i es converteixen en estreles. És en aquest context on hem d'examinar els sentiments provocats pels famosos de la xarxa a la Xina actual, així com la influència que exerceixen aquestes estreles.

En l'estudi de les reflexions i teories sobre l'afecte, les emocions i els sentiments (Smith i Schneider, 2009) trobem referències a filòsofs socials del segle XVII, XVIII i XIX, com Descartes, Montesquieu, Bentham, Pascal, La Mettrie i Darwin, entre d'altres. 
Els primers sociòlegs, com Comte, Durkheim, Fourier, Marx, Sombart, Simmel i Weber, també afirmaven que el control emocional és una altra forma de disciplina i que afecta pràctiques, relacions i cosmovisions socials de manera recíproca i dinàmica (Gross, Feldman Barrett, 2011). Aquestes qüestions també han sigut abordades en gran mesura des de distintes perspectives de la sociologia contemporània, principalment per Bourdieu, Giddens, Foucault, Agamben i Esposito. En aquest sentit, es considera que Brian Turner i David Le Breton van ser els precursors dels estudis socials sobre el cos, com ho són els estudis de Kemper, Hochschild, Scheff, Collins i Illouz sobre les emocions.

D'altra banda, autors clàssics com Nietzsche, Merleau-Ponty, Spinoza i Marx ofereixen una perspectiva distinta sobre les tradicions teòriques que normalment sustenten els estudis en aquest camp. No obstant això, hi ha autors contemporanis que suggereixen altres enfocaments, com és el cas de Goffman, Simmel i Elias en sociologia, amb Derrida, Butler i Deleuze en filosofia, i amb Freud, Lacan i Zizek en la psicoanàlisi.

La popularitat de les celebritats d'internet a la Xina indica quina direcció ha pres la normalitat. Ara ja no sols veiem els famosos en la televisió i les pel-lícules, i les estreles s'identifiquen clarament amb la gent normal, al contrari del que passa amb les estreles de Hollywood. La ràpida evolució de les xarxes socials permet al públic triar els seus ídols segons els seus gustos. Les noves estreles de la xarxa saben com captar l'atenció del públic compartint-hi les seues pròpies experiències i emocions. ${ }^{6}$

En el cas de les estreles d'internet xineses, també pot apreciar-se la interacció dels seus cossos amb la societat. Els seus cossos i les seues imatges en la xarxa poden circular, descarregar-se i copiar-se com si foren símbols o models. Aquestes estreles formen part integrant del dia a dia dels consumidors. D'altra banda, com

6 Sobre «emotion management», vegeu Hochschild (1990). Ideology and emotion management: A perspective and path for future research. En T. D. Kemper (ed.), Research agenda in the sociology of emotions (p. 117-142). Nova York: University of New York Press. a persones normals, som esclaus de la cultura de les celebritats d'internet. En conseqüència, cada vegada més gent acaba sent fan (voluntari o involuntari) i identificant-se íntimament amb les persones famoses. En aquest punt sembla adequat observar les postures i modalitats del cos en un context més ampli.

La tensió entre cos-individu, cos-subjectiu i cos-social és una de les claus per a comprendre les relacions entre les geometries dels cossos i les gramàtiques d'acció que formen part de la Xina, d'Àsia i del Sud Global. El fenomen de les estreles d'internet també crea tensions quan s'inscriu en la perspectiva corporal des del punt de vista de les sensacions. La lògica d'«atraure fans» en forma d'hordes de «likes» pot ser senzilla i pràctica, però també pot generar problemes i tensions socials. Com afirma Wang Bing:

En aquest circ col-lectiu, un text curt o un vídeo pot obtenir molts clics i amb ells una gran difusió, molts comentaris i inclús tornar-se viral. El nombre de seguidors ha esdevingut la puntuació de les estreles. En aquest sentit, els nous mitjans s'han convertit en una factoria digital de famosos. (Wang Bing, 2018: 47)

Com hem dit, aquest article pretén dilucidar les pràctiques de les celebritats d'internet a la Xina per tal d'entendre la política de sensibilitats actual.

\section{CELEBRITATS: COS, SENSACIONS I PERCEPCIONS}

L'informe «2018 China Online Celebrity Cconomic Development Insight Report», ${ }^{7}$ publicat per Sina Weibo i e-Research, conclou que l'escala de la indústria de les estreles d'internet no para d'expandir-se i que estan sorgint molts àmbits nous. La quantitat de celebritats creix i l'edat dels fans es redueix. Per a aquestes estreles, la publicitat s'ha convertit en la manera més fàcil de guanyar diners i expandir la seua influència, tal com reconeixen els propis anunciants. Des del punt de

72018 China Online Celebrity Economic Development Insight Report (en línia): http://report.iresearch.cn/wx/report.aspx?id=3231 consultat el 21 de març de 2019. 
vista de gènere, el nombre d'estreles masculines va créixer un 49,9\% el 2008. Més de la meitat de les estreles són de grans ciutats com Pequín, Xangai o Canton. També cal remarcar que generalment es tracta de persones amb un nivell d'educació alt. Segons aquest estudi, el 77,6 \% té estudis de grau i el $13 \%$ compta amb un màster. L'anàlisi de Daily Web, la classificació de estreles d'internet xineses revela que en $2018^{8}$ els cinc primers llocs els ocupaven 回忆专用 小马甲 («small vest for the memory»), papi酱 («papi sauce»)，小野妹子学吐槽 («gossip from sister Xiao Ye»), 我的前任是极品 («a crazy ex») i 同道大叔 («tong dao Auncle»). Aquests estranys noms suggereixen que no es tracta d'actors o actrius, sinó de persones normals amb molts fans a la xarxa. Com que no són professionals de la vida mediàtica, quan aquestes persones es fan famoses, sovint tenen problemes si els seus actes i característiques personals entren en conflicte amb la seua identitat social.

Imatge 1

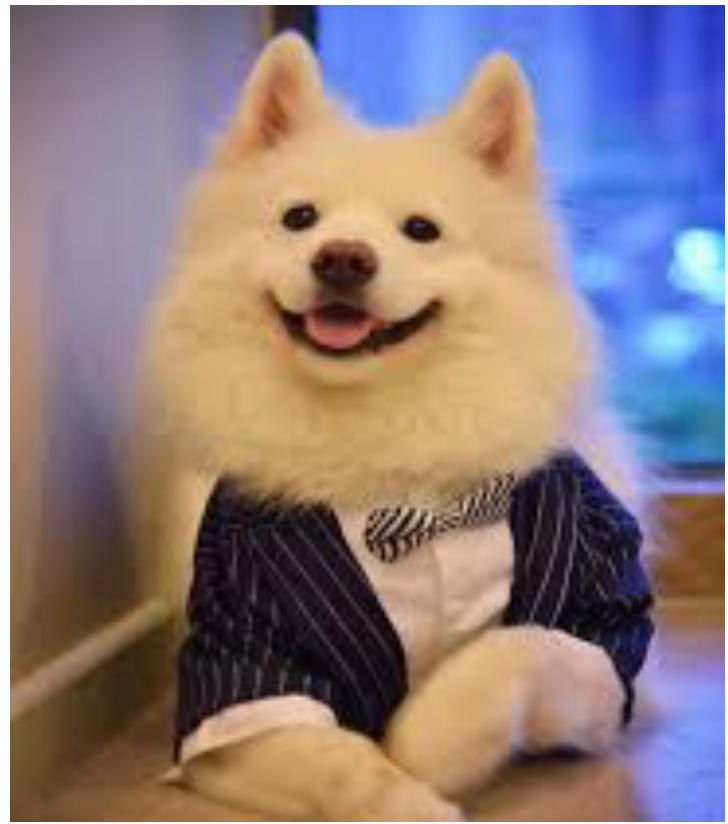

回忆专用小马甲 «8 (small vest for the memory») Font: http :m.gaochengnews.net//wanghong/24647.hmtl

8 Classificació de les estreles d'internet a Xina en 2018 (en línia): http://www.enet.com.cn/article/2018/0818/ A20180818052679.html consultat el 21 de març de 2019.
Imatge 2

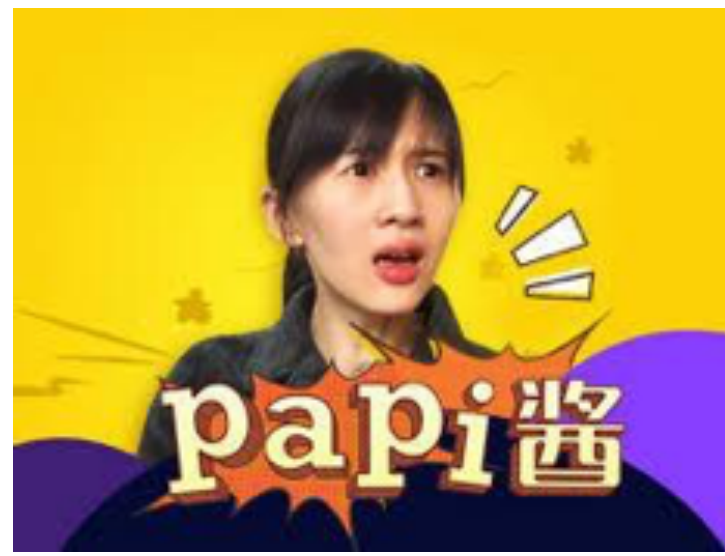

papi酱 («papi sauce») Font: http://www.ikanchai.com/article/20160713/88465.shtm

Les estreles d'internet han ideat una imatge emocional que els ha permés estrényer forts llaços amb els consumidors. Poden connectar-se a la xarxa per acompanyar els seus fans i usar el seu estil únic per a captar encara més fans, per exemple amb missatges, imatges, fotos, vídeos i emissions en directe que mostren les seues sensacions, opinions i experiències sobre determinats productes o notícies concretes. Moltes celebritats se sotmeten a operacions de cirurgia estètica, es maquillen o es posen robes extravagants en directe per a complaure els seus fans.

L'aplicació de vídeos curts Douyin (llançada amb el nom A.me al setembre de 2016) ofereix un espai perquè s'expressen no només les estreles, sinó també la gent normal. Concebuda originàriament com una aplicació per a vídeos musicals fets pels usuaris, hui en dia Douyin té múltiples funcions i cobreix des de bromes fins a mascotes, passant per acrobàcies esportives. Els vídeos no poden superar els quinze segons i l'aplicació ofereix infinitat d'eines d'edició, filtres i efectes, com la càmera lenta o l'efecte desenfocat.

Les impressions teixides per les estreles d'internet creen sensacions que originen dos mons: un d'in-

9 Sempre usa el perfil del seu gos NiuNiu per a fer riure el seu públic. 
tern i un altre d'extern. La naturalesa del primer és social i subjectiva, mentre que el segon cobreix el que podríem denominar «el món natural». Aquestes configuracions es creen en una tensió dialèctica entre impressions, percepcions i els seus resultats, de manera que confereixen a les sensacions el «significat» d'un sobrant o excés que els acosta i situa més enllà de la dialèctica.

En la societat xinesa contemporània es veu el reflex del cos-individu, cos-subjectiu i cos-social des de la popularitat de les celebritats d'internet. El seu cos-subjectiu és l'autoexpressió del seu cos-individu, però afecta el cos-subjectiu múltiple dels fans. El cos d'aquests fans és també un cos social que exerceix una gran influència sobre la societat xinesa. Per exemple, Papi 酱 va estudiar a l'Acadèmia Central d'Art Dramàtic de Xina, on va obtenir els títols de grau i de màster. Ha treballat en la indústria de l'espectacle com a actriu i com a assistent de direcció. Ara, sota el pseudònim «Papi 酱» és una celebritat d'internet que va esdevenir famosa penjant vídeos sarcàstics en les xarxes socials. Utilitza l'autoexpressió per a discutir temes candents i té «opinions pròpies». Per això, el seu cos-imatge no és individual i fractal, sinó que té «funcions socials» que expressen el cos «diari», comú. D'aquesta manera, el seu exemple serveix d'inspiració a altre persones normals, que usen el seu cos de manera artística i acaben convertint-se en celebritats.

El 2014, una artista anomenada Zhou Jie va crear una exhibició personal denominada «36 dies», on apareixia dormint despullada en un espai d'exposició. Això es va convertir en un esdeveniment social i molta gent la va criticar, ja que dubtaven si es tractava d'art d'acció o d'art eròtic. Així, el seu cos no és l'autoexpressió dels seus sentiments, sinó més aviat un cos social observat per la societat.

Las estreles d'internet intenten aprofitar el seu cos-imat$g e$ per a influir en els «sentiments naturals» dels seus fans, i en fer-ho, construeixen el cos-pell de la gent $\mathrm{i}$ generen un cos-moviment semblant a la sociabilitat.
Imatge 3

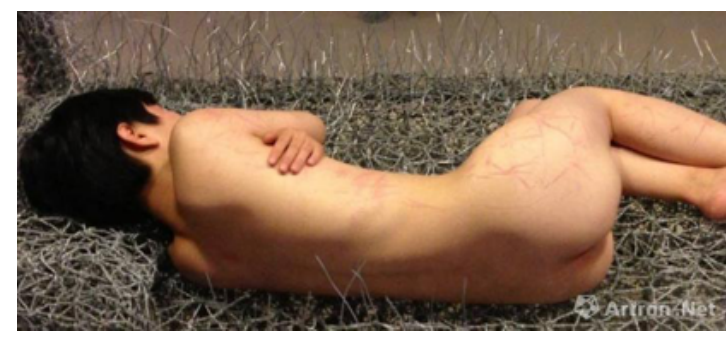

Exhibició de Zhou Jie «36 dies» Font: https://news.artron.net/20170725/n946895.html

\section{REFLEXIONS FINALS}

Sullivan i Kehoe (2017) recalquen la importància de la moralitat de les celebritats, atés que «a la Xina, l'Estat, que promou des de fa temps models de conducta pel seu patriotisme, heroisme o comportament exemplar, utilitza les celebritats com a vehicle per a fomentar el nacionalisme, les virtuts tradicionals i l'afany de modernitat. Ha identificat les celebritats com a proveïdores de «béns espirituals», i les exhorta a «actuar en consciència, comportar-se respectuosament $i$ assumir la iniciativa de donar exemple a la societat». Les celebritats xineses han de crear imatges positives i ser model espiritual per al públic. Per això, és important entendre la política de les emocions com una estratègia per a construir la sensibilitat social.

A la Xina s'espera que les sensibilitats reflectisquen els «valors socialistes fonamentals», com ara prosperitat, democràcia, civisme, harmonia, llibertat, igualtat, justícia, estat de dret, patriotisme, dedicació, integritat i amistat. Sens dubte, un context semblant condiciona la producció i el consum d'estreles d'internet a la Xina. En aquest sentit, es considera que les celebritats són el vehicle i l'expressió de la «veu dels de dalt» per a educar i governar la gent. D'altra banda, la màquina ofereix a la gent normal l'oportunitat de ser estreles en concursos de talents d'internet, de manera que les celebritats també representen la «veu de les classes mitjana i baixa» en qüestions socials, de justícia i igualtat.

Les xarxes socials xineses tenen les seues pròpies eines, com ara WeChat, QQ o Weibo, entre altres, on actuen les estreles d'internet. Les microcelebritats per a microentorns i les masses mostren dos camins per a 
convertir la imatge personal d'un mateix en «popularitat», «fama» $\mathbf{i}$ «reconeixement». La cultura de «captar l'atenció» s'ha convertit en un fenomen planetari i forma part d'una vida viscuda a través d'imatges que consagren la noció de gaudi i gratificació instantània. Les imatges i pràctiques de les estreles d'internet xineses encarnen actituds col-lectives i s'espera que obeïsquen les polítiques xineses de gestió d'internet i que contribuïsquen a la societat en general. En aquest sentit, la gent normal té més possibilitats de convertir-se en una persona famosa i fer sentir la seua veu.
Finalment, la societat 4.0 està modelant l'economia digital. Les sensacions i emocions de les celebritats d'internet xineses exalcen la sociabilitat i mobilitzen les sensibilitats socials. Aquestes celebritats obrin una finestra a la vida diària del poble xinés actual revelant-ne les inquietuds, les preocupacions, les esperances i els somnis en un país que està avançant ràpidament en el camí de l'alta tecnologia, un reflex dels passos de gegant que ha donat en els últims quaranta anys.

\section{REFERÈNCIES BIBLIOGRÀFIQUES}

Gross J., Feldman Barrett, L. (2011). Emotion generation and emotion regulation: one or two depends on your point of view. Emotion Review, 3, 8-16.

Hochschild, A. R. (1990). Ideology and emotion management: A perspective and path for future research. En T. D. Kemper (ed.), Research agenda in the sociology of emotions (p 117-142). Nova York: University of New York Press.

Jiang, Y. (2012). Cyber-nationalism in China: Challenging Western media portrayals of internet censorship in China. Adelaida: University of Adelaide Press.

Li, L. (2018). China's manufacturing locus in 2025: With a comparison of «Made-in-China 2025» and «Industry 4.0». Technological Forecasting and Social Change, 135, 66-74.

Lien, C. H. i Cao, Y. (2014). Examining WeChat users' motivations, trust, attitudes, and positive word-of-mouth: Evidence from China. Computers in Human Behavior, 41, 104-111.

Lin, Z. (2018). Performance of the body: Chinese female celebrity's practices of self-governance. Gender, Place \& Culture, 25(5), 775-778. DOI: 10.1080/0966369X.2018.1461080

Pearl, S. i Polan, D. (2015). Bodies of digital celebrity. Public culture, 27, 1 (75), 185-192.

Smith, H. i Schneider, A. (2009). Critiquing models of emotions. Sociological Methods \& Research, 37(4), 560-89.

Scribano, A. i Lisdero, P. (ed.) (2019). Digital labour, society and politics of sensibilities. Londres: Palgrave Macmillan.

Scribano, A., Timmermann López, F., Korstanje, M. E. (ed.) (2018). Neoliberalism in multi-disciplinary perspective. Londres: Palgrave Macmillan.

Scribano, A. (2018). Politics and emotions. Houston: Studium Press LLC.

Scribano, A. (2017). Normalization, enjoyment and bodies/emotions: Argentine sensibilities. Nova York: Nova Science Publishers.

Scribano A. (2007). Mapeando interiores: Cuerpo, conflicto y sensaciones. Córdoba: Sarmiento Editor.

Scribano, A. (1998). Complex societies and social theory. Social Science Information, 37, 3, 493-532.

Sullivan, J. i Kehoe, S. (2019). Truth, good and beauty: the politics of celebrity in China. The China Quarterly, 237, 241-256.

Wang Bing (2018). The culture of celebrities, the consumption and the affective labour of the fans: Three cases of the Wanghong phenomenon in China. New Comments Tianfu, 3, 144-151.

Wang Junbin (2018). In the era of celebrities online: Between the expression of oneself and wise study. Monthly Education Research, 12, 31-43. DOI: 10.3966/168063602018120296003. Xu, X. i Pratt, S. (2018). Social media influencers as endorsers to promote travel destinations: an application of self-congruence theory to the Chinese Generation Y. Journal of Travel \& Tourism Marketing, 35(7), 958-972. DOI: 10.1080/10548408.2018.1468851 
Zhang, G. i De Seta, G. (2018). Being «red» on the internet: The craft of popularity on Chinese social media platforms. En C. Abidin i M. Lindsay Brown (ed.), Microcelebrity Around the Globe (p. 57-67). Bingley: Emerald Publishing Limited.

Zhang Yanhui i Chen Fuwen (2018). Influences of the different types of advertisement on customers' awareness and consumption: The case of the Internet celebrities and their advertisement. Quarterly Administration and Commerce, 19(3), 257-282. Zhang, W. (2016). The Internet and new social formation in China: Fandom publics in the making. Abingdon-on-Thames: Routledge.

\section{NOTA BIOGRÀFICA}

\section{Adrián Scribano}

Adrián Scribano és investigador principal de CONICET, el Instituto de Investigaciones Gino Germani de la Facultat de Ciències Socials de la Universidad de Buenos Aires i director del Centro de Investigaciones y Estudios Sociológicos (CIES).

\section{Zhang Jingting}

Zhang Jingting, és doctora en Ciències Socials per la Universidad de Buenos Aires. Ara és professora i està fent el programa del postdoctorat en SISU. És membre del grup de Grupo de Sociología del Cuerpo y Emociones (GESEC) en l'Instituto de Investigaciones Gino Germani de la Universidad de Buenos Aires i membre del Centro de Investigaciones y Estudios Sociológicos CIES. 